\title{
Creativity in Modern Education
}

\author{
Duli Pllana ${ }^{1,2, *}$ \\ ${ }^{1}$ Mathematics, Passaic Art and Science Charter High School, Passaic, USA \\ ${ }^{2}$ Math in General Education, Eastern International College, Bellville, USA \\ *Correspondence: 190 East Clinton Avenue, Bergenfield, NJ 07621, USA. E-mail: dulipllana65@gmail.com
}

Received: March 10, 2019 Accepted: April 1,2019 Online Published: April 20, 2019

doi:10.5430/wje.v9n2p136 URL: https://doi.org/10.5430/wje.v9n2p136

\begin{abstract}
There will be elaborated several facts about creativity in Twenty First-Century educational reforms in six countries (The US, India, Chile, Mexico, China, and Singapore). The crucial source of the content in the paper relies on the book, "Teaching and Learning for the Twenty-First Century" (Reimeres and Chung, 2016). Nevertheless, my exploration of creativity in modern education in the six countries has a limited range. Creativity depends on three meaningful factors of education such as equality, quality and implementing modern educational reforms. The paper sheds light on similarities and differences of six countries that they experience with the three factors (equality, creativity, and implementing modern educational reforms). All countries strive to apply equality in the whole country, although, none of the countries has employed equality throughout the nation. Some countries made better progress on applying equality in education, and others are facing many obstacles with equal education throughout the country. Creativity is significant to every educational system, and it is interrelated with equality and applying modern education. The US system of education applies creativity in a few school districts. Other countries state creativity in their curriculum, but they do not use it in the classrooms at all. Six countries have different economic development, and different economic demands; therefore, they have different approaches to implementing modern educational reforms. Despite the fact all countries have dissimilarities with implementing creativity in educational reforms, they all know creativity's weight in modern education. Creativity as a first step of the innovation that defines the progress of education especially accelerates the growth of the entire economy within a society.
\end{abstract}

Keywords: creativity, equality, quality, modern education

\section{Introduction}

Development of technological innovation changes rapidly the world's economy. A great number of countries in the world accepted that education is a powerful tool to enhance life and stimulate the economy. My focus will be on the educational reforms (applying creativity inside classrooms) in six countries, the U.S, India, China, Singapore, Mexico. Six countries recognized the fact that reforms in education are necessary actions to prepare skilled workers to deal with the modern economy (Reimeres and Chung, 2016). Educational reform's intention in all countries is to reach the same target with different strategies. Each country has different needs to make more progress in a learning domain (cognitive competency, interpersonal competency, and intrapersonal competency) than the other one. Comparing educational reforms in six countries reflect their similarities and differences. In all countries the goal of education corresponds with the workforce demand and civic participation; the curricula contribute positively to national development, the reform is initiated and supervised by the government. On the other hand, the differences are reflected in implementing reforms. All countries have a different culture, level of development of the economy, and different approaches to reform, which are reflected in their educational outcome. Nonetheless, all countries realized that providing modern education with creativity amplifies innovations in the modern economy.

Education in modern time has many aims; since the paper contains a small volume, I will pay attention to the main purpose of creativity in modern education. The fundamental goal of global education is equality in education. In general, the main purpose of educational system centers on preparing students for life, providing with working skills (increases work force in a nation,) and citizenship. According to the article, What is the Purpose of Education in 21 Century says, "Critical thinking, creativity, interpersonal skills and a sense of social responsibility; all of them influence success in life, work, and citizenship" (Strauss, 2015). All three elements are interrelated with students' 
learning, growing academically, and practicing future professions at a high level. Creativity requires several preconditions to function within a system of education. Equal education promises all students would have the same chance competing justly with the opportunity of employing creativity rationally.

\section{Creativity in Education}

Educators do not understand creativity well, thus, they struggle to apply in their lesson plan. Before we go any further, let try defining creativity with a simple clear definition. Creativity is the ability to create something new from nothing. According to the book "Teaching and Learning for the Twenty-First Century" creativity like critical thinking, and higher order of thinking skills belong into cognitive competencies. Creativity and critical thinking differ from each other. The difference between them is evident if we analyze their definitions. Critical thinking in education is when we analyze deeply a lesson or questions as part of the lesson. Higher order thinking in education is based on Bloom's Taxonomy (Shaughnessy, n. d.). The US and China's system of education prefer higher order thinking. On the other hand, only The US school system involves creativity in a few school districts.

Indian system of education reform offers a universalism (compulsory education for all up to age fourteen) in education; the advancement of teaching strategies made very little growth. Teachers are not prepared to teach creativity, but they are working toward finding new ways of teaching. In the article, Creativity in Education System, says," Teacher should introduce innovative ways of teaching by giving priority to activity-based learning and enable learning with experience and observation" (Chetty, n. d.) Many academics are inspiring leaders of education on applying creativity in education. The businessman, Soumitra Dutta (Chetty, n. d.), claims the Indian system of education restricts creativity and innovation in education. He goes a step further by the encouraging system of education in India to remove the restriction on freedom, creativity, and innovation.

In the formal education in India, they have gifted education for a long period of time. Indian Researchers did a sort of investigation on the creativity in the gifted education without solid scientific evidence. The article Gifted Education in India states two significant statements, "Professionals working with gifted students recognize that creativity is a salient issue and an important component for giftedness, ..., while some further stress that creativity is actually the highest form of giftedness" (Roy, 2016). The two statements are in contradiction because the silent issue of giftedness and the highest form of giftedness do not associate well with each other. The highest property of a quantity will be identified easily because is vivid. On the other hand, creativity is a silent issue it would be hard to recognize. Usually, creative individuals do not live a good impression as a gifted student. Students who are active in solving problems fast or answering questions quickly resonates with gifted students, but it does not necessarily mean they are creative.

Current Scholars and educators in The US realized the fact that creativity results in shaping modern education. In general, the system in the US is unique. Creativity is present just in a few school districts. The article What Happened to Creativity? Education Stifles Originality, in the classes student is told what to create and what to correct. Moreover, the article states, "Schools have been killing creativity out of students for years and only expect creativity to be exposed when called upon" (Forray, 2017). Schools district in the US are more interested in standardizing tests that require specific answers, and leave no space for creativity. Usually, students just seek answers, so they do not get in the depth of the concepts, and they do not analyze 'what happens if' questions.

The modern education in the United States obtains too many standardized tests (students are overwhelmed with state tests), which determines the students' academic performance, but does not evaluate creativity. Usually creative students struggle with standardizing test since they are trying to figure out convergent answers. According to the article Standardized Tests "Narrow," Don't Assess Creative Skills, Sternberg Contends says, "While these tests do account for analytical skills, they do not assess (creative skills, practical skills, or wisdom-based ethical skills)" (Isenberg, 2015). Standardized tests require analytical skills analyzing a process that leads to a unique answer. In general, multiple question tests dictate a learning system that hunts a single right answer. Strategies solving or answering on questions of standardize test limits our thinking to converge toward a single solution.

Creativity in Chile educational curriculum (primary and secondary schools) is evident in a few subjects. Chapter three of the book, "Teaching and Learning for the Twenty-First Century" says," (Bellei \& Morawietz, 2016). Cognitive processes are addressed by most of the subjects, while the development of creativity is confined to Arts and Language and Physical Education, and only complemented by technological Education through innovation projects" (Bellei \& Morawietz, 2016). Creativity mention as a cognitive competency in the Chilean curriculum; educators are not prepared professionally to apply creativity even in Art and Language and Physical education. Nonetheless, critical thinking may be applying in Chilean education since the curriculum has improved significantly. 
Despite the improvement of education in Chile there are not established conditions to implement creativity in their schools' districts. They still struggle with providing qualitative education in the entire country. Based on the article, Chile's Educational Reform: The Struggle Between Nationalization and Privatization claims, "This system does not meet the criterion of quality because it does not encourage further private school improvement, and it still prevents the public schools from improving" (Zelaya, 2015). There are neglected principles of creativity; the basic conditions for creativity is equality and quality of education. Officials in Chile are more concerned to implement basic constituents of education. Instead of moving forward with reforming education, there are setbacks, which prolongs implementing a modern education meticulously. Thus creativity has limited space in the system of education in Chile.

Mexico's Government revealed its relevance to making a revolution in their system of education with the goal decreasing the gap between its system of education (developing country) and developed countries' education. Educational reformation in Mexico started to take shape in 2013 (Educational Revolution in a Century, n. d.). Based on the article, Mexico Urges Teachers, education Authorities and Parents to Undertake Most, Important Educational Revolution in a Century: EPN, learning strategy was to memorize. The article points some statements of the president regarding the organizing teaching plans. Also, the President mention reorganizing learning model, "Children will learn, rather than memorizing, through a new pedagogical approach" The reorganization of teaching and learning corresponds with cognitive competency (elements of applying critical thinking, and some elements of Bloom's taxonomy). Latino systems of education do not apply creativity in their schools because they are more focused on other basic educational concerns (Educational Revolution in a Century, n. d.).

Experienced educators in Mexico leave their jobs with extremely low income for jobs with higher income. Teaching jobs do not guarantee an average life per average family. As a result, Mexican education suffers from shortage in professional teachings. The article, Mexican Education: A Mere Simulation clarifies, "The dropout among qualified teachers also is very high, especially among those with less than five years' experience. "Salaries are so low that many grab the first non-teaching opportunity that comes up, an Oaxaca private school teacher explained" (Stout, 2016). Low educators' motivation on thinking about teaching and learning does not support substantial progress in equal education. The absence of investment in education jeopardizes equality, especially suffocates pathways of creativity. Positive outcomes of education including creativity are correlated with investments, hence, creativity is not in the equations of education in Mexico.

Culture in China manifested creativity throughout history in several subjects (disciplines). Creativity as a first step in innovations is an inseparable part of Chines culture. Nonetheless, the system of education in China does not exhibit creativity in education (Review of China's Education Reform, 2017). Students have long hours in schools, and they spend many hours doing homework. Definitely, studying the long period of time influences on performing well in standardized tests. Another hand, studying long hours does not contribute to creativity. "The education in Mainland China, Hong Kong, and generally in Asia has very long school days and a lot of homework, which I think kills initiative and creativity, Vesterback said in an interview in Shenzhen" (Chen, 2017). The resistance of creativity in primary and secondary education probably will diminish creativity in other levels of education. Despite the opposition of creativity in education, Chinese culture will keep creativity alive in other sectors.

Modern Education expands all its components in the Twenty-First Century counting creativity. Consequently, China goes with contemporary current in education like The US. Both countries apply higher order thinking skills instead of creativity in their education system. Indeed, they are avoiding creativity from early age schools. Creativity at an early age has an advantage. Students might foster creativity (self-expressing themselves) by practicing at a younger age. The article, Developing young children's creativity: what can we learn from research? Claims, "Most writers on creativity agree that it is possible to encourage or indeed to inhibit the development of creativity in young children" (Sharp, 2004). People who exercised since childhood self-expressing themselves are more successful than others who didn't practice. Educators know every subject or field necessities practice on reaching the maximum results. Thus, educators will keep creativity informally in curricula of modern education in all six countries.

Singapore's students' performance consistency in PISA's tests is on the top of all countries. Additionally, teachers in Singapore exercise teaching occupation steadily for a long period of time, so they are able to produce positive results in teaching and learning. Nonetheless, they are implementing insufficiently creativity in their schools. Nowadays Singapore stands better academically in global education than South Korea and Japan. The article, Singapore Graduate Facing Creative Gap, states "However, these are not clear indicators that Singapore will maintain her globe competitive edge. What will set them apart from other countries with similar levels of knowledge and skills like South Korea and Japan? Are creativity and innovation" (Sinniah, 2017)? Singapore schools are more involved 
with transmitting knowledge, skills, and practices. This kind of activities does not leave enough space to express creativity neither higher-order cognitive skills.

\section{Conclusion}

In all six countries reflects similarities and differences in reforming education in twenty-first century. The main purpose of education is to expand curricula with respect to labor demands, changes in civic participation, and progressing technological inventions. Similarities are reflected in many directions such as government initiating reforms, striving equality and quality in education, and applying all learning domains of modern education. Equality and quality of education is a powerful key to open the door for creativity. Nowadays, equality and quality are friable in all six countries' education and do not assure a complete application of creativity in modern education. The United States and China employ higher order thinking as an alternative for creativity, while other countries do not bother so much with it. Indian education still deals with disparity with equality in education. Therefore, they try to find creativity with talented schools despite the fact the creativity is not correlated with talent. Everybody knows creativity, but a small number of them have skills to use it. This is a reason why all countries involve creativity in their curricula; nonetheless, just a few schools in The United States are able to demonstrate in the school districts. Mexico and Chile are in the same category as India; they face many issues with protesters who complain about inequality in education. Chile mentions creativity in art because art attracts creativity more than other subjects. In Chile's education system does not have evidence they support the presence of creativity in their school districts. Singapore stands well with equality and quality of education, and their students' performance in a standardized test is outstanding. The attention of Singapore's education on standardized tests took away creativity from their educational system. Since each country has different economic development and different cultures, they approach employing educational reforms in their education systems differently. Innovations in all segments of society follow the footsteps of creativity and modify it as a final product. Therefore, six countries gave a lot of space to creativity in curricula even though essentially they fail to materialize it in the school districts.

\section{References}

Ben Isenberg. (October 27, 2015). Standardized Tests "Narrow," Don't Assess Creative Skills, Sternberg Contends retrieved from https://www.hamilton.edu/news/story/standardized-tests-narrow-dont-assess-creative-skills-sternberg-contends

Caroline Sharp. (Fall 2004). Developing young children's creativity: what can we learn from research? Retrieved from https://www.nfer.ac.uk/publications/55502/55502.pdf

Celia Chen. (2017, December). China's Education System Kills Initiative and Creativity-Says CoFounder of Angry Birds Mobil-game. Retrieved from https://www.scmp.com/frontpage/international

Cristian Bellei \& Liliana Morawietz. (2016). Strong Content, Weak Tools, Twenty-First-Century Competencies in the Chilean Educational Reform: Teaching and Learning for the Twenty-First Century. Cambridge, Massachusetts, Harvard Education Press.

Educational Revolution in a Century: EPN. Retrieved from https://www.gob.mx/presidencia

Fernando M. Reimeres \& Connie K. Chung. (2016). Teaching and Learning for the Twenty-First Century. Cambridge, Massachusetts: Harvard Education Press.

Michael F. Shaughnessy, (n. d). Higher order skills vs critical skills. Retrieved from https://educationinjapan.wordpress.com/homeschooling-afterschooling/higherthinking-skills-vs-critical-thinking -skills/

Paromita Roy. (May, 16 2016). Gifted education in India retrieved from https://www.tandfonline.com/doi/full/10.1080/2331186X.2017.1332815

Priya Chetty, Creativity in Education System. Retrieved from www.projectguru.in

Robert Joe Stout (March 19, 2016). Mexican Education: A Mere Simulation. Retrieved from https://newpol.org/mexican-education-mere-simulation/

Samuel Forray. (2018, October). What Happened to Creativity? Education Stifles Originality. Retrieved from www.villanovana.com

Valerie Strauss, (2015, February). What is the purpose of Education in 21 Century. Retrieved from 
https://www.washingtonpost.com/?noredirect=on

Vannia J. Zelaya, (2015). Chile's Educational Reform: The Struggle Between Nationalization and Privatization. Retrieved from https://digitalcommons.pepperdine.edu/cgi/viewcontent.cgi?article=1119\&context=ppr

Viva Sinniah. (2017). Singapore Graduate Facing Creative Gap. Retrieved from https://sbr.com.sg/ 